\title{
Study on the Factors Influencing the Extraction of Chenodeoxycholic Acid from Duck Bile Paste by Calcium Salt Method
}

\author{
Xiangzheng $\mathrm{Hu}(\mathbb{D}, \mathrm{Na}$ Feng, and Jiaqi Zhang \\ College of Food Engineering \& Biotechnology, Tianjin University of Science and Technology, Tianjin 300457, China \\ Correspondence should be addressed to Xiangzheng Hu; huxzh@tust.edu.cn
}

Received 26 June 2017; Revised 5 December 2017; Accepted 25 December 2017; Published 1 March 2018

Academic Editor: Alberto Figoli

Copyright (C) 2018 Xiangzheng Hu et al. This is an open access article distributed under the Creative Commons Attribution License, which permits unrestricted use, distribution, and reproduction in any medium, provided the original work is properly cited.

\begin{abstract}
New extraction technology of chenodeoxycholic acid from duck bile paste by calcium salt was investigated. The optimum conditions of extraction were determined by orthogonal experimental design. The results indicated that influencing factors on the extraction efficiency of chenodeoxycholic acid were as follows: hydrogen peroxide, methyl alcohol, glacial acetic acid, and calcium chloride. The optimum extracting conditions of chenodeoxycholic acid were $1000 \mathrm{~mL}$ amount of methyl alcohol, $50 \mathrm{~mL}$ amount of hydrogen peroxide, $500 \mathrm{~mL}$ amount of $20 \%$ calcium chloride, and $600 \mathrm{~mL}$ amount of $60 \%$ glacial acetic acid for a quantity of duck paste. The yield of chenodeoxycholic acid was $30 \%$.
\end{abstract}

\section{Introduction}

Chenodeoxycholic acid ( $3 \alpha, 7 \alpha$-dihydroxy- $5 \beta$-cholanic acid, CDCA) is one of the dominant bile acids in human and animals bile. CDCA has significant anti-inflammatory, antitussive, and expectorant effects [1]; CDCA is used for the medical treatment of metabolic diseases for it can reduce or dissolve cholesterol gall-stones in vivo [2]. CDCA is also the precursor of ursodeoxycholic acid (UDCA) which is another effective drug for gallstone treatment $[3,4]$. UDCA is used to treat a variety of acute and chronic liver diseases [5-8]. The method of synthesizing of UDCA with CDCA is highly efficient. The cost of producing UDCA by this method is the lowest. At present, the UDCA is mainly produced by this method [9-11].

CDCA is the main organic ingredient in the bile of chickens, ducks, geese, and other poultry. It can be obtained from poultry bile by extracting technology [12] or synthesizing from cholic acid, dehydrocholic acid, and so on. Initially, the synthesis of CDCA from CA is the main source of CDCA.

In Europe, chemical synthesis of CDCA with CA as raw material is the main source of CDCA. In the past 10 years in China, the extraction of CDCA from chicken bile was the main source of CDCA. Although the number of chickens and ducks in China is very large, different techniques are required for extracting CDCA from chicken bile and duck bile because there is a large difference in the composition of chicken and duck bile. Few literatures report on the method of extracting CDCA from duck bile.

A typical process for preparing CDCA is as follows: esterifying of saponified bile acid, acetylating of bile acid ester, removal of intermediate product by using organic solvent, crystallizing of acetylated ester of CDCA, deprotecting, and crystallizing in organic solvent. The entire process is complex, a large number of organic solvents (e.g., ethyl acetate, gasoline) are consumed, and the yield of the final product is low. At present, in China, because of being used as a raw material for CDCA extraction, the price of chicken bile is high. The duck bile is treated as a waste by a slaughterhouse for the lack of related technology, even though the content of CDCA in chicken bile and duck bile is similar. In order to solve the environmental pollution problems of duck bile and make it easy to store and transport, many slaughterhouses turn duck bile into gall ointment which can be used as a feed.

The content of CDCA in duck bile is over $25 \%$. Moreover, extracting CDCA from duck bile can bring considerable economic benefits. This paper is aimed at designing an efficient way to find out the primary factors influencing the 
yield of CDCA from duck bile paste. We speculate that this aim could be easily realized through the combination of an orthogonal experimental design method.

\section{Materials and Methods}

2.1. Materials. Duck bile paste was obtained from Xiayi Kangda Biochemical Raw Materials Co., Ltd. Anhydrous methanol $(\mathrm{MeOH})$, hydrogen peroxide $\left(\mathrm{H}_{2} \mathrm{O}_{2}\right)$, calcium chloride $\left(\mathrm{CaCl}_{2}\right)$, sodium hydroxide $(\mathrm{NaOH})$, glacial acetic acid, ethanol, chloroform $\left(\mathrm{CHCl}_{3}\right)$, and ethyl acetate were supplied by Tianjin Chemical Reagent Company (Tianjin, China), and all of them were of analytical grade; the standard sample of CDCA was from inspection bureau biological project of China.

2.2. Apparatus and Detection. FTS135-FTIR Spectrometer (Bio-Rad Instruments) was used to determine the infrared spectra, and the measurements were carried out by the KBr method. AVIII 600 NMR Spectrometer (Bruker A.G) was used to determine the nuclear magnetic spectrum. The conditions were $23^{\circ} \mathrm{C}$ and $400.4 \mathrm{MHz}$, and TMS was used as the internal standard. For high-performance liquid chromatograph (Agilent), the chromatographic column was a Waters Symmetry C18 $(4.6 \mathrm{~mm} \times 150 \mathrm{~mm}, 5 \mu \mathrm{m})$. The mobile phase was $0.2 \%$ formic acid-methanol $(20: 80, \mathrm{v} / \mathrm{v})$ and flow rate was $1.0 \mathrm{~mL} / \mathrm{min}$. The column temperature was maintained at $30^{\circ} \mathrm{C}$. The standard curve was used to determine the purity of the CDCA by HPLC [13-15].

2.3. Orthogonal Experimental Design [16]. Orthogonal experimental design is a popular method to deal with the test, including multiple factors and levels. It has been successfully applied to many fields for acquiring the optimum level group. The key of this method is making an orthogonal design table based on the reasonable and representative levels of the investigated factors. This method can help us to select the representative cases for lowering the number of test cases. In this work, the number of investigated factors is four and they have three levels; an orthogonal design table $L_{9}\left(3^{4}\right)$ is needed, reducing the number of test cases from 81 to 9 .

2.4. Process. After the solution of duck bile paste in $\mathrm{CH}_{3} \mathrm{OH}$ was heated to $65^{\circ} \mathrm{C}$ with stirring for $1 \mathrm{~h}$, the solution was cooled to the room temperature. Insoluble substance was filtered out. The $10 \% \mathrm{H}_{2} \mathrm{O}_{2}$ solution was added to the filtrate with stirring. After $30 \mathrm{~min}, 20.0 \%(\mathrm{w} / \mathrm{v}) \mathrm{CaCl}_{2}$ solution was added to the solution; the $\mathrm{pH}$ value was adjusted to 11 with $5 \%(\mathrm{w} / \mathrm{v}) \mathrm{NaOH}$ solution. The mixture was stirred for $30 \mathrm{~min}$; the precipitation was formed. The precipitate was collected by centrifugation and then was added to $60 \%$ glacial acetic acid. The solution was heated and kept reflux until all solid was dissolved. A yellow transparent solution was got. This liquid was poured into water after cooling, and the CDCA solid was obtained by filtration. Finally, CDCA was purified by recrystallizing in $\mathrm{EtOH} / \mathrm{CHCl}_{3}$ mixed solution. The results show that the amount of $\mathrm{H}_{2} \mathrm{O}_{2}, \mathrm{MeOH}$, glacial acetic acid, and $\mathrm{CaCl}_{2}$ added affects the extraction of CDCA in duck

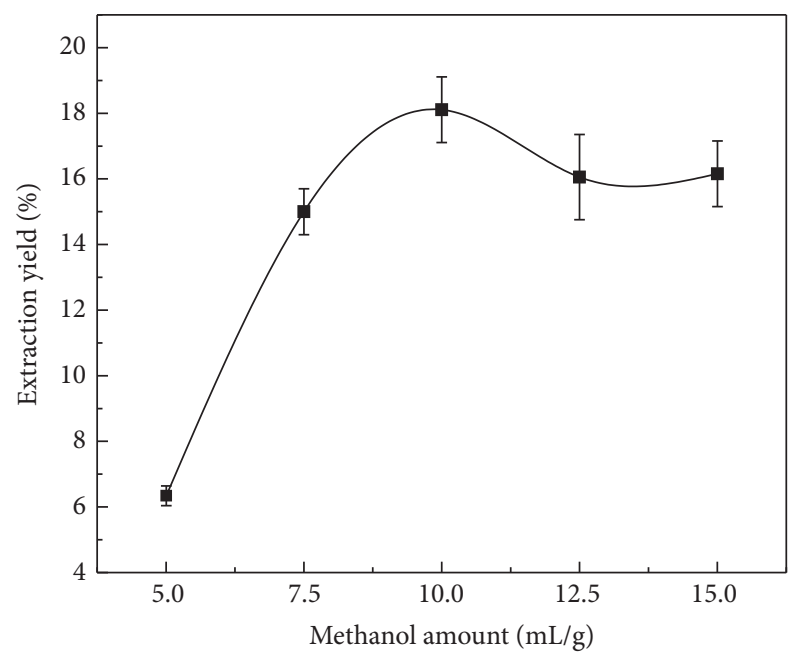

FIGURE 1: Effect of different amount of methanol on the yield of CDCA.

bile paste. The single factor experiment conditions and orthogonal experiment conditions were determined based on the preliminary experimental results.

2.5. Calibration Curves. The solutions were prepared by accurately weighing $50 \mathrm{mg}$ CDCA standard and dissolving it in $50 \mathrm{~mL}$ methanol. The working standard solution was prepared by diluting the mixed standard solution with $\mathrm{MeOH}$ to a series of proper concentrations. The standard solutions were stored at $4^{\circ} \mathrm{C}$ until use.

The sample solutions were prepared by accurately weighing $25 \mathrm{mg}$ CDCA sample and dissolving it in $50 \mathrm{~mL} \mathrm{MeOH}$. The resultant solution was filtered through a $0.45 \mu \mathrm{m}$ syringe filter (Type Millipore, USA); $20 \mu \mathrm{L}$ of the filtrate was injected into the HPLC system. The sample solutions were stored at $4^{\circ} \mathrm{C}$. The working standard solutions were brought to room temperature and $50 \mu \mathrm{L}$ was injected into HPLC for the construction of calibration curves. A linear regression equation was obtained by plotting the logarithms of peak area responses versus logarithms of concentrations, in $\mu \mathrm{g} / \mu \mathrm{L}$.

\section{Results and Discussion}

\subsection{Influence of Different Amount of Reagent on Yield}

3.1.1. The Influence of $\mathrm{MeOH}$ on Yield. The duck bile pastes $100 \mathrm{~g}, 100 \mathrm{~mL} \mathrm{H}_{2} \mathrm{O}_{2}$ solution, $300 \mathrm{~mL} 20.0 \% \mathrm{CaCl}_{2}$ solution, and $600 \mathrm{~mL} 60 \%$ glacial acetic acid were added to the system. The influence of $\mathrm{MeOH}$ on yield was shown in Figure 1.

When the amounts of $\mathrm{H}_{2} \mathrm{O}_{2}, \mathrm{CaCl}_{2}$, and glacial acetic acid were fixed, the yield of CDCA increased with the increasing amount of $\mathrm{MeOH}$ in a certain range. When the amount of $\mathrm{MeOH}$ reached about $1000 \mathrm{~mL}$, the yield reached the maximum value. After that, with the dosage of $\mathrm{MeOH}$ kept increasing, the yield remained stable. The results indicated that smaller amount of $\mathrm{MeOH}$ could not dissolve the paste completely. When the solvent was more enough, the yield 


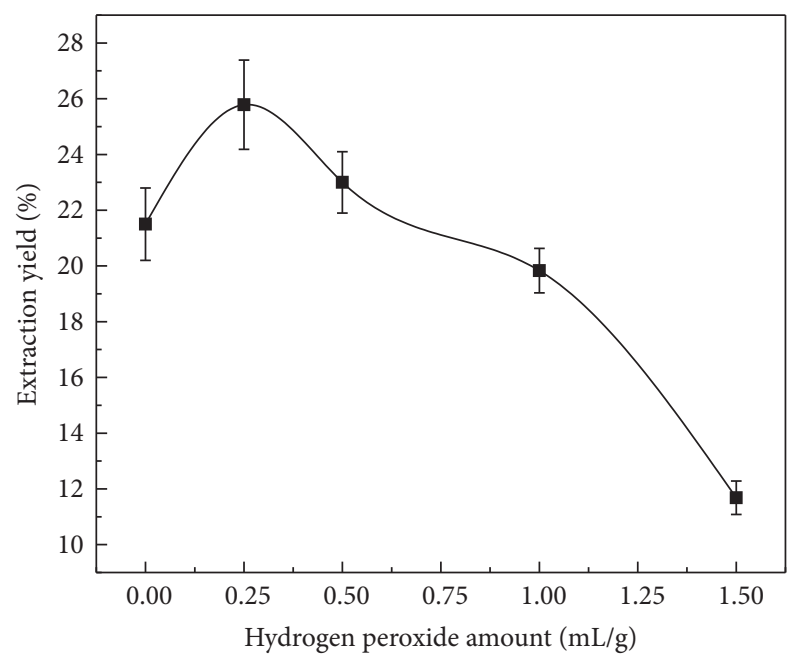

FIGURE 2: Effect of different amount of hydrogen peroxide on the yield of CDCA.

was not increased. So taking the cost of production into consideration, $1000 \mathrm{~mL}$ was suitable.

3.1.2. The Influence of $\mathrm{H}_{2} \mathrm{O}_{2}$ on Yield. The duck bile paste $100 \mathrm{~g}$ was dissolved in the system composed of $1000 \mathrm{~mL} \mathrm{MeOH}$, $300 \mathrm{~mL} 20.0 \% \mathrm{CaCl}_{2}$, and $600 \mathrm{~mL} 60 \%$ glacial acetic acid. The impact of $\mathrm{H}_{2} \mathrm{O}_{2}$ amount on yield was shown in Figure 2.

When the amount of the $\mathrm{H}_{2} \mathrm{O}_{2}$ was added to $25 \mathrm{~mL}$, the yield of CDCA reached the maximum value. After that the yield of CDCA decreased with the increasing of $\mathrm{H}_{2} \mathrm{O}_{2}$ solution. This situation may be as a result of the large amount of $\mathrm{H}_{2} \mathrm{O}_{2}$ oxidizing CDCA so as to reduce the yield of CDCA. But this may be less effective toward the decolorization of CDCA if the amount was too small. So the appropriate dosage was $50 \mathrm{~mL}$

3.1.3. The Influence of $\mathrm{CaCl}_{2}$ on Yield. The duck bile paste $100 \mathrm{~g}$ was dissolved in the system composed of $1000 \mathrm{~mL}$ $\mathrm{MeOH}, 100 \mathrm{~mL} \mathrm{H}_{2} \mathrm{O}_{2}$, and $600 \mathrm{~mL} 60 \%$ glacial acetic acid. The influence of $\mathrm{CaCl}_{2}$ amount on yield was shown in Figure 3.

When the amount of $20 \% \mathrm{CaCl}_{2}$ solution was $400 \mathrm{~mL}$ or less, the yield increased with the increasing amount of $\mathrm{CaCl}_{2}$ solution; when the amount of $\mathrm{CaCl}_{2}$ solution was over $400 \mathrm{~mL}$, the yield decreased with the increasing of $\mathrm{CaCl}_{2}$ solution. It indicated that the yield of CDCA reached the maximum value when $400 \mathrm{~mL} \mathrm{CaCl}$ solution was added. When the amount of $\mathrm{CaCl}_{2}$ was not enough, the CDCA would not form $\mathrm{CaCl}_{2}$. On the contrary, if the amount was too large, it would generate $\mathrm{Ca}(\mathrm{OH})_{2}$, which could adsorb $\mathrm{CaCl}_{2}$ and decrease the yield of CDCA.

3.1.4. The Influence of Glacial Acetic Acid on Yield. The duck bile paste $100 \mathrm{~g}$ was dissolved in $1000 \mathrm{~mL} \mathrm{MeOH}$, and then $100 \mathrm{~mL} \mathrm{H}_{2} \mathrm{O}_{2}$ and $600 \mathrm{~mL} 20.0 \% \mathrm{CaCl}_{2}$ solution were added with stirring. The influence of glacial acetic acid amount on yield was shown in Figure 4.

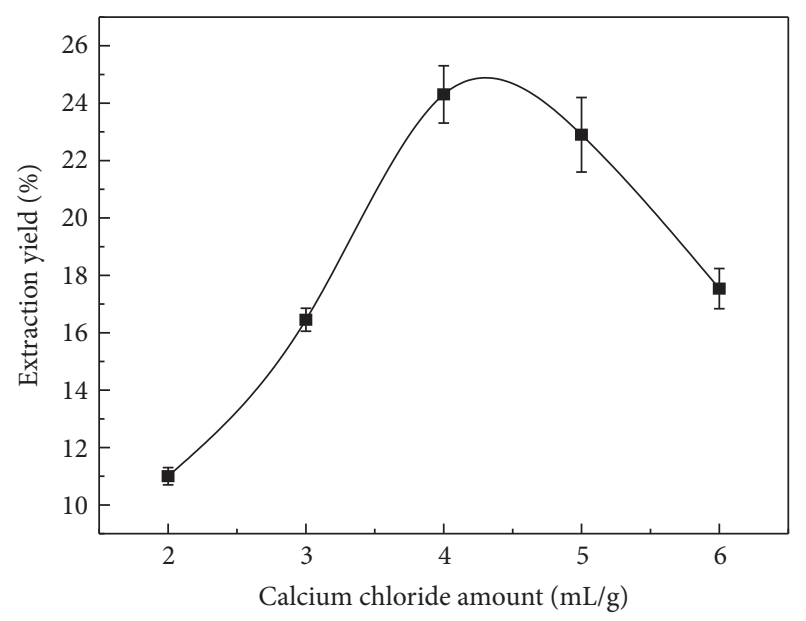

FIGURE 3: Effect of different amount of $20 \%$ calcium chloride on the yield of CDCA.

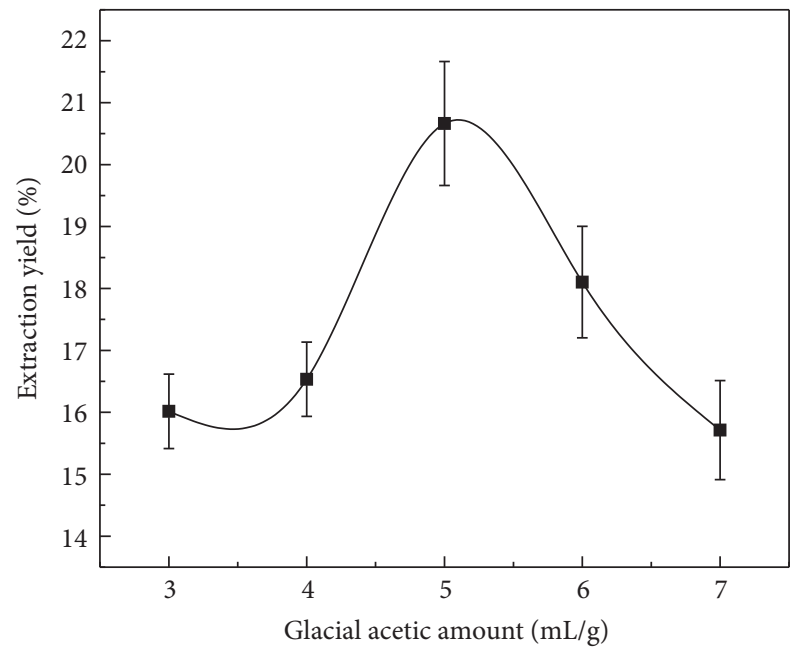

FIGURE 4: Effect of different amount of $60 \%$ glacial acetic acid on the yield of CDCA.

When the amount of glacial acetic acid added was less than $500 \mathrm{~mL}$, the yield of CDCA increased with the increasing amount of glacial acetic acid. When the amount of glacial acetic acid added was $500 \mathrm{~mL}$ or more, the yield of CDCA decreased with the increase of glacial acetic acid amount. A small quantity of glacial acetic acid could neutralize calcium salt and lead to release of CDCA. When the amount of glacial acetic acid reached $500 \mathrm{~mL}$, the calcium salt of CDCA just hydrolyzed completely and the additive amount was suitable. While the amount of glacial acetic acid continuously is increased, CDCA would be dissolved, leading to yield decrease.

3.2. Orthogonal Test. Based on the above experimental data, taking the yield of CDCA as an index, orthogonal experimental design of four factors' three levels was taken to optimize the extracting conditions of CDCA. The factors and levels are shown in Table 1. $L_{9}\left(3^{4}\right)$ orthogonal test results of intuitive 


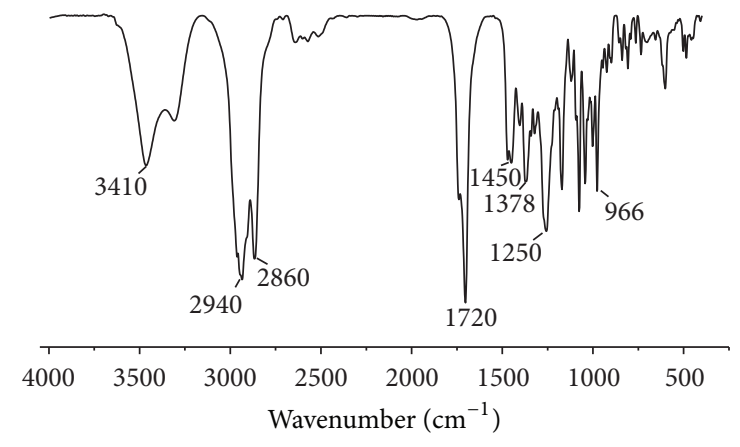

Figure 5: The IR of CDCA of sample product.

TABLE 1: Factors and levels for orthogonal test.

\begin{tabular}{|c|c|c|c|c|}
\hline Level & $\begin{array}{c}\text { A } \\
\text { Methanol } \\
(\mathrm{mL})\end{array}$ & $\begin{array}{c}\mathrm{B} \\
\mathrm{H}_{2} \mathrm{O}_{2}(\mathrm{~mL})\end{array}$ & $\begin{array}{c}\mathrm{C} \\
\mathrm{CaCl}_{2}(\mathrm{~mL})\end{array}$ & $\begin{array}{c}\mathrm{D} \\
\text { Glacial acetic } \\
\text { acid }(\mathrm{mL})\end{array}$ \\
\hline 1 & 750 & 25 & 300 & 400 \\
\hline 2 & 1000 & 50 & 400 & 500 \\
\hline 3 & 1250 & 100 & 500 & 600 \\
\hline
\end{tabular}

analysis were carried out as in Table 2. Variance analysis of orthogonal experiment results was shown in Table 3. The analysis of variance was performed by statistical software SPSS 12.0.

The results showed that factors influencing the extraction of CDCA from duck bile paste by calcium salt were as follows: hydrogen peroxide, methyl alcohol, glacial acetic acid, and calcium chloride. The optimum extracting conditions of this process were that every $100 \mathrm{~g}$ duck bile paste collocated with $1000 \mathrm{~mL} \mathrm{MeOH}, 50 \mathrm{~mL} \mathrm{H}_{2} \mathrm{O}_{2}, 500 \mathrm{~mL} 20 \% \mathrm{CaCl}_{2}$ solution, and $600 \mathrm{~mL} 60 \%$ glacial acetic acid. A parallel experiment was performed three times under the conditions of the best combination of factors; the yield was $30 \%, 29 \%$, and $31 \%$, and average value was $30 \%$; it was significantly higher than single factor tests results.

\subsection{Characterization}

\subsubsection{Structure Characterization}

(1) IR Spectrogram. The IR spectrogram of sample was shown in Figure 5.

In FTIR spectra, the appearance of a broad stretching vibration band at $3410 \mathrm{~cm}^{-1}$ for hydrogen groups and C$\mathrm{H}$ groups, $\mathrm{C}=\mathrm{O}$ stretching vibrations, bend vibration for hydrogen groups, $\mathrm{C}-\mathrm{H}$ bend vibrations, $\mathrm{C}-\mathrm{O}$ in carboxyl groups at 2940,1720,1450,1378, and $1250 \mathrm{~cm}^{-1}$ (close to the literature value [17]) determined that the obtained substance was CDCA.

(2) ${ }^{1} H N M R$. The ${ }^{1}$ HNMR spectrogram of sample was shown in Figure 6.

${ }^{1} \mathrm{HNMR}$ spectra were recorded in $\mathrm{CDCl}_{3}$ on a AVIII600 NMR Spectrometer (Bruker A.G), using TMS as internal

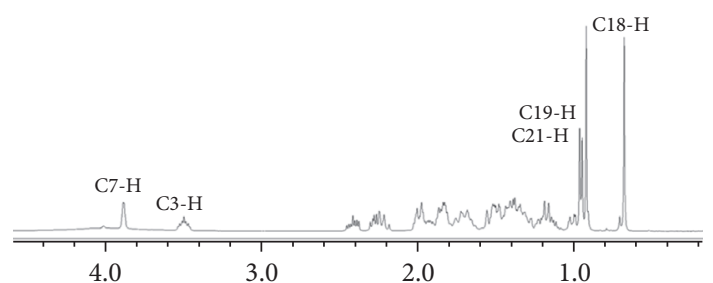

Figure 6: The HNMR spectrum of sample product.

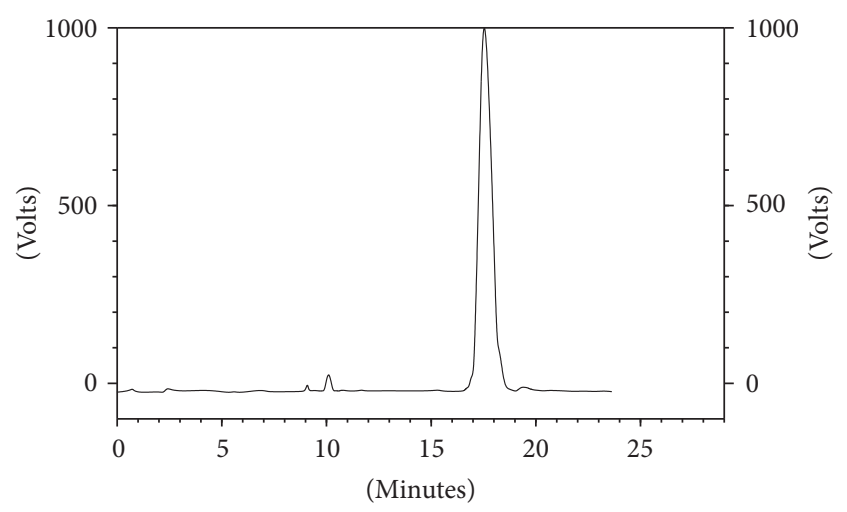

FIGURE 7: The HPLC spectrum of sample product.

standard. Figure 6 showed the characteristic peak value $(\delta \mathrm{H}$ $0.68\left(\mathrm{~s}, 3 \mathrm{H}, 18-\mathrm{CH}_{3}\right), 0.92\left(\mathrm{~s}, 3 \mathrm{H}, 19-\mathrm{CH}_{3}\right), 0.95(\mathrm{~d}, 3 \mathrm{H}, 21-$ $\mathrm{CH}_{3}$ ), $3.49(\mathrm{br}, 1 \mathrm{H}, 3-\mathrm{H})$, and $3.87(\mathrm{br}, 1 \mathrm{H}, 7-\mathrm{H})$ ) (close to the literature value [18]). By the ${ }^{1}$ HNMR spectrogram and the related literature [19], the obtained substance is determined to be CDCA.

3.3.2. The Detection Results of HPLC. The product was determined by HPLC. As shown in Figure 7, the retention time of CDCA was $17.3 \mathrm{~min}$. Small impurity peaks can be seen at $10 \mathrm{~min}$, and some of the corresponding materials were likely contained in the raw material. The regression equation of CDCA was $Y=0.7229 X+16.908(r=0.9997)$; CDCA in the $0.3 \mu \mathrm{g}-0.7 \mu \mathrm{g} / \mu \mathrm{L}$ range showed a good linear relationship. According to the regression equation, the purity of CDCA was $97.2 \%$.

\section{Conclusions}

The detection data proved that the optimum extracting conditions were that every $100 \mathrm{~g}$ duck bile paste collocated with $1000 \mathrm{~mL} \mathrm{MeOH}, 50 \mathrm{~mL} \mathrm{H}_{2} \mathrm{O}_{2}$, $500 \mathrm{~mL}$ of $20 \% \mathrm{CaCl}_{2}$ solution, and $600 \mathrm{~mL}$ of $60 \%$ glacial acetic acid. Under the optimal extraction conditions, the yield of CDCA can reach $30 \%$.

Over the years, CDCA is mainly obtained from chicken bile. In this paper, CDCA was extracted from the duck bile paste and the optimal extraction conditions were determined by orthogonal test. The process is simple and suitable for industrial production, what is more, it can enhance the added value of livestock and poultry products. 
TABLE 2: Analysis of $L_{9}\left(3^{4}\right)$ test results.

\begin{tabular}{|c|c|c|c|c|c|}
\hline Test number & A & B & $\mathrm{C}$ & $\mathrm{D}$ & $\begin{array}{c}\text { Productivity } \\
\%\end{array}$ \\
\hline 1 & 1 & 1 & 1 & 1 & 24 \\
\hline 2 & 1 & 2 & 2 & 2 & 24 \\
\hline 3 & 1 & 3 & 3 & 3 & 17 \\
\hline 4 & 2 & 1 & 2 & 3 & 29 \\
\hline 5 & 2 & 2 & 3 & 1 & 28 \\
\hline 6 & 2 & 3 & 1 & 2 & 18 \\
\hline 7 & 3 & 1 & 3 & 2 & 24 \\
\hline 8 & 3 & 2 & 1 & 3 & 25 \\
\hline 9 & 3 & 3 & 2 & 1 & 13 \\
\hline$K 1$ & 65.20 & 76.81 & 66.53 & 64.92 & \\
\hline$K 2$ & 74.83 & 77.12 & 66.1 & 65.61 & \\
\hline$K 3$ & 60.89 & 46.99 & 68.29 & 70.39 & \\
\hline$k 1$ & 21.73 & 25.60 & 22.18 & 21.64 & \\
\hline$k 2$ & 24.94 & 25.71 & 22.03 & 21.87 & \\
\hline$k 3$ & 20.30 & 15.66 & 22.76 & 23.46 & \\
\hline Range $R$ & 4.64 & 10.05 & 0.73 & 1.82 & \\
\hline Order & \multicolumn{5}{|c|}{$\mathrm{B}>\mathrm{A}>\mathrm{D}>\mathrm{C}$} \\
\hline Combination & \multicolumn{5}{|c|}{$\mathrm{A}_{2} \mathrm{~B}_{2} \mathrm{C}_{3} \mathrm{D}_{3}$} \\
\hline
\end{tabular}

$K i$ represents the sum of number $i$ of various factors $(i=1,2,3), k i$ represents the average of number $i$ of various factors $(i=1,2,3), R$ represents the difference between the maximum and the minimum of $k i$ of various factors.

TABLE 3: Variance analysis of orthogonal experiment.

\begin{tabular}{lccccc}
\hline Factors & SS & $f$ & $F$ & $F$ threshold & 19 \\
A & 33.96 & 2 & 37.83 & 19 & $*$ \\
B & 199.68 & 2 & 222.46 & 19 & $*$ \\
C & 0.90 & 2 & 1 & 19 & \\
D & 5.92 & 2 & 6.59 & & \\
Error & & 2 & & \\
\hline
\end{tabular}

* indicates that this factor has significant influence on the experiment.

\section{Conflicts of Interest}

The authors declare that they have no conflicts of interest.

\section{Acknowledgments}

This work was supported by the Tianjin Science and Technology Project Funds (nos. 14ZXCXSY00109 and 14RCHZSY00159).

\section{References}

[1] R. A. Cao, L. Y. Li, and L. P. Zhang, "Study on the extraction technology of chenodeoxycholic acid from porcine bile," Food Research and Development, vol. 32, no. 4, pp. 12-15, 2011.

[2] A. F. Hofmann, "Bile acids: trying to understand their chemistry and biology with the hope of helping patients," Hepatology, vol. 49, no. 5, pp. 1403-1418, 2009.

[3] J. Wan, J. He, and X. J. Cao, "A novel process for preparing pure chenodeoxycholic acid from poultry bile," Journal of Industrial and Engineering Chemistry, vol. 18, no. 1, pp. 65-71, 2012.
[4] B. Alenezi, E. Lamoureux, L. Alpert, and A. Szilagyi, "Effect of ursodeoxycholic acid on granulomatous liver disease due to sarcoidosis," Digestive Diseases and Sciences, vol. 50, no. 1, pp. 196-200, 2005.

[5] G. Paumgartner and U. Beuers, "Mechanisms of action and therapeutic efficacy of ursodeoxycholic acid in cholestatic liver disease," Clinics in Liver Disease, vol. 8, no. 1, pp. 67-81, 2004.

[6] G. H. Sauter, K. Thiessen, K. G. Parhofer, C. Jüngst, S. Fischer, and D. Jüngst, "Effects of ursodeoxycholic acid on synthesis of cholesterol and bile acids in healthy subjects," Digestion, vol. 70, no. 2, pp. 79-83, 2004.

[7] M. P. Guarino, S. Carotti, M. Sarzano et al., "Short-term ursodeoxycholic acid treatment improves gallbladder bile turnover in gallstone patients: A randomized trial," Neurogastroenterology \& Motility, vol. 17, no. 5, pp. 680-686, 2005.

[8] K. D. Lindor, K. V. Kowdley, E. J. Heathcote et al., "Ursodeoxycholic acid for treatment of nonalcoholic steatohepatitis: results of a randomized trial," Hepatology, vol. 39, no. 3, pp. 770-778, 2004.

[9] M. F. Lu, W. C. Yin, F. D. Wang, and D. M. Peng, "Improved synthesis of ursodeoxycholic acid," Chinese Journal of Pharmaceuticals, vol. 46, no. 10, pp. 1058-1059, 2015. 
[10] H. M. Xu, "A process for preparing ursodeoxycholic acid," CN104193792A, 2014.

[11] Y. X. Zhu, L. Jie, Y. Wu, and L. Hai, "Synthesis of a key intermediate for ursodeoxycholic acid," Chemical Reagents, vol. 34, no. 4, pp. 366-368, 2012.

[12] Y. H. Liu and X. Z. Hu, "Extraction technique of chenodeoxycholic acid from duck bile paste," Journal of Tianjin University of Science \& Technology, vol. 24, no. 3, pp. 43-45, 2004.

[13] Y. H. Yeh and D. F. Hwang, "High-performance liquid chromatographic determination for bile components in fish, chicken and duck," Journal of Chromatography B: Biomedical Sciences and Applications, vol. 751, article 1, 2001.

[14] B. Amplatz, E. Zöhrer, C. Haas et al., "Bile acid preparation and comprehensive analysis by high performance liquid chromatography-high-resolution mass spectrometry," Clinica Chimica Acta, vol. 464, pp. 85-92, 2017.

[15] J. Kandrac, S. Kevresan, J. K. Gu, M. Mikov, J. P. Fawcett, and K. Kuhajda, "Isolation and determination of bile acids," European Journal of Drug Metabolism and Pharmacokinetics, vol. 42, article 157, 2006.

[16] W. Zuo, E. Jiaqiang, X. L. Liu, Q. G. Peng, Y. W. Deng, and H. Zhu, "Orthogonal experimental design and fuzzy grey relational analysis for emitter efficiency of the micro-cylindrical combustor with a step," Applied Thermal Engineering, vol. 103, pp. 945-951, 2016.

[17] X. J. Pan and X. M. Zhang, "A new process for isolation and purification of chenodeoxycholic acid from pig's bile paste," Hebei Medical Journal, vol. 28, no. 2, pp. 147-148, 2006.

[18] Q. H. Deng, Y. Yao, T. Liu, L. L. Jing, and Z. C. Li, "The extraction and purification of three kinds of bile acids from pig bile," Chinese Journal of Biochemical Pharmaceutics, vol. 33, no. 4, pp. 405-407, 2012.

[19] D. V. Waterhous, S. Barnes, and D. D. Muccio, "Nuclear magnetic resonance spectroscopy of bile acids. Development of two-dimensional NMR methods for the elucidation of proton resonance assignments for five common hydroxylated bile acids, and their parent bile acid, 5 beta-cholanoic acid," The Journal of Lipid Research, vol. 26, article 1068, 1985. 

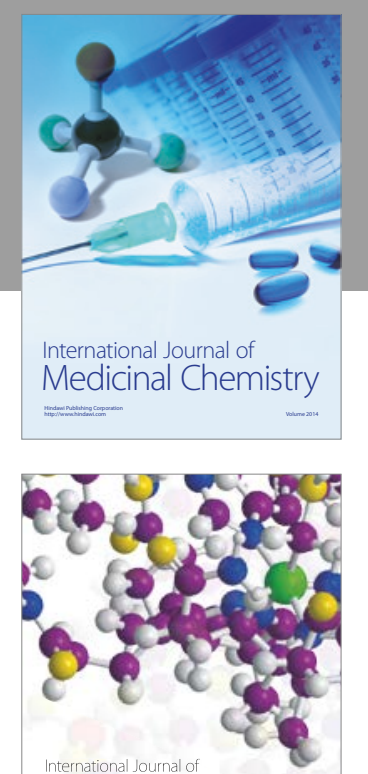

Carbohydrate Chemistry

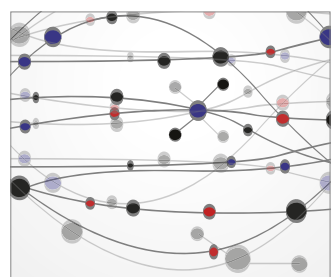

The Scientific World Journal
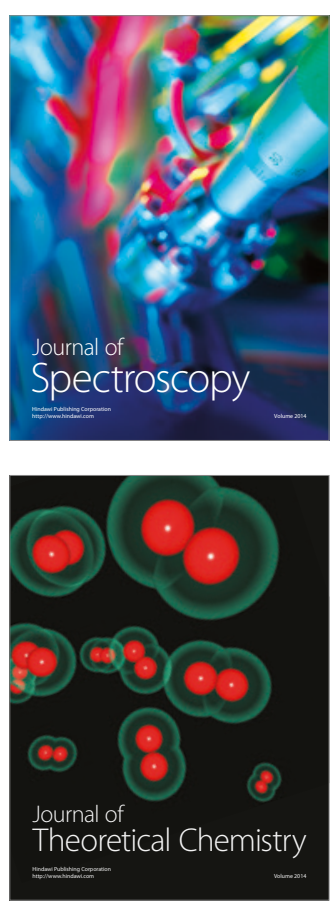
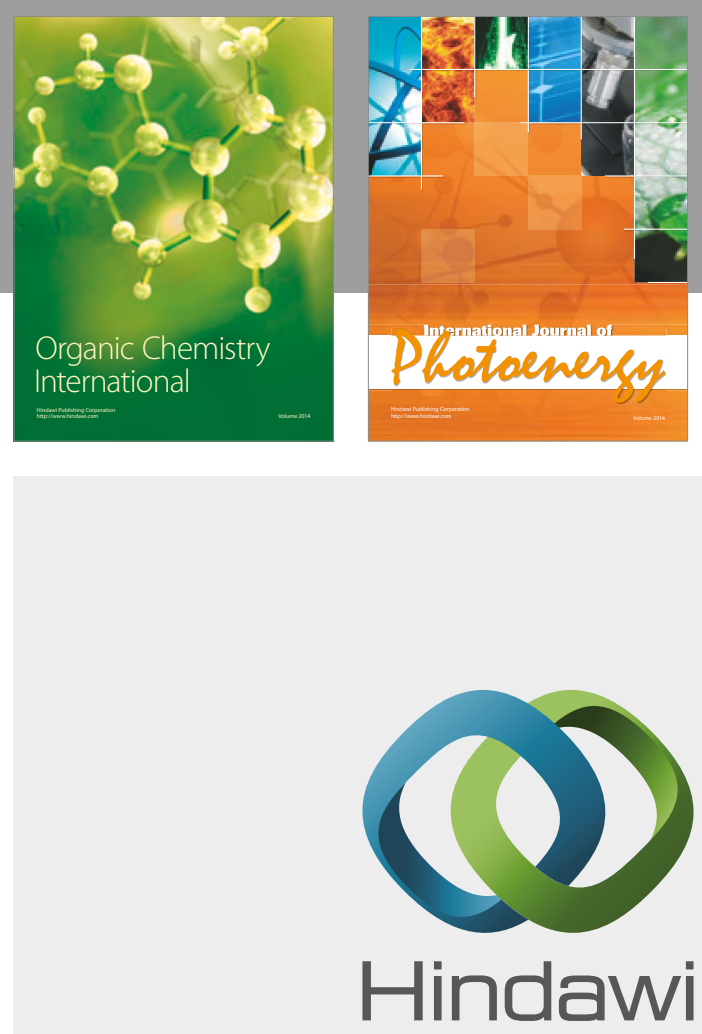

Submit your manuscripts at

https://www.hindawi.com

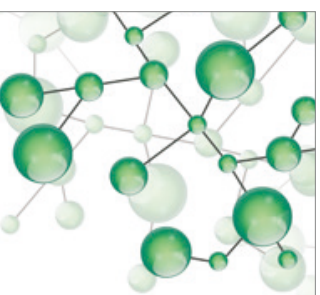

International Journal of

Inorganic Chemistry

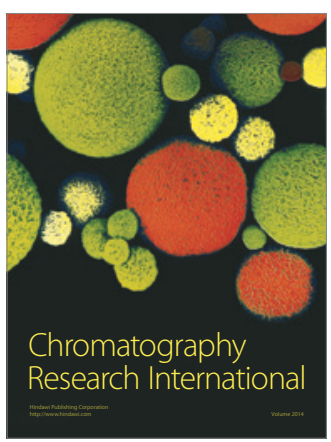

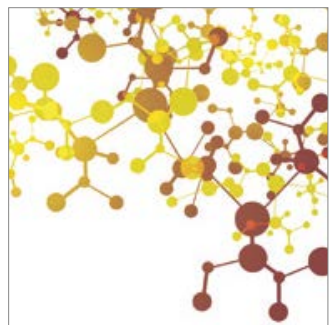

Applied Chemistry
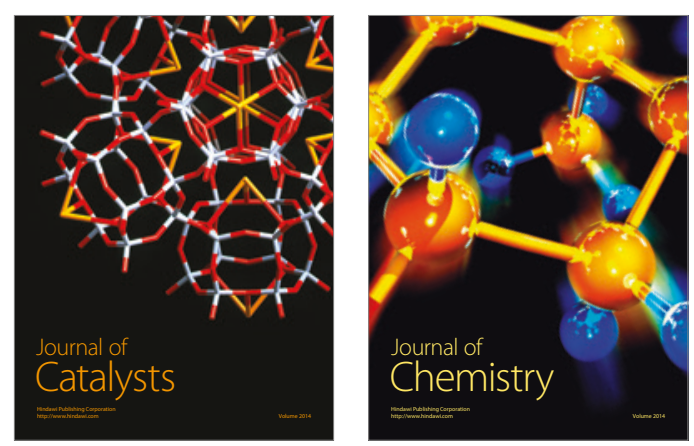
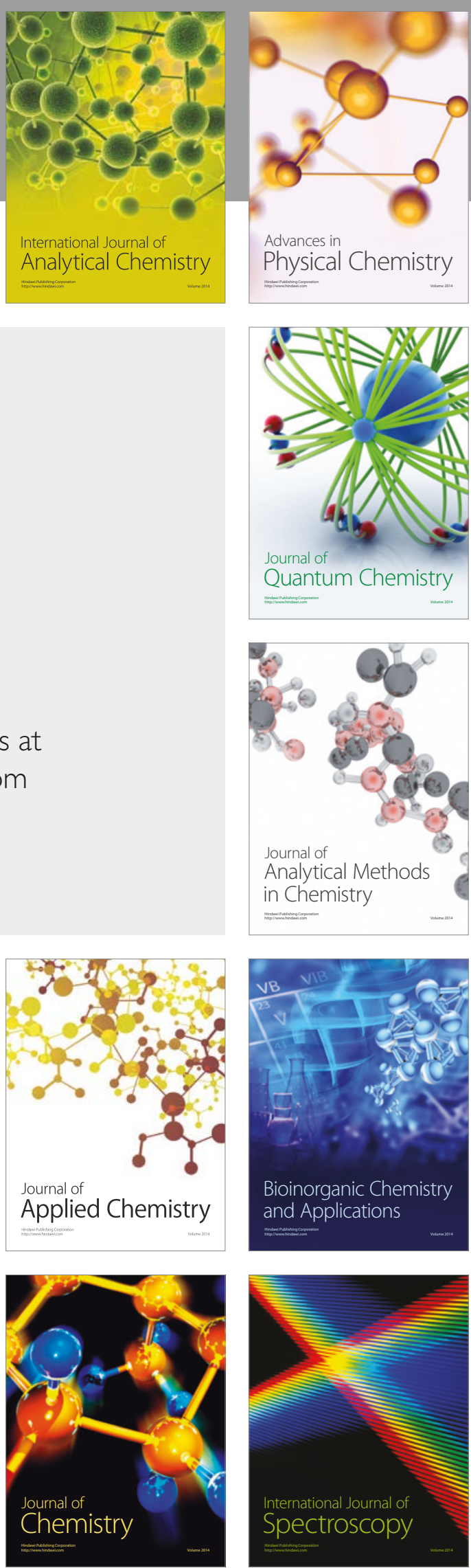